\title{
Synthesis of Disperse Dyes from Pyridone and Resorcinol Coupled to Diazotized 2-Amino-4-chloro-5-formylthiazole and Application to Polyester
}

\author{
Yusuf Y. Lams, ${ }^{1}$ P. O. Nkeonye, ${ }^{2}$ K. A. Bello, ${ }^{2}$ M. K. Yakubu, ${ }^{2}$ and A. O. Lawal $^{3}$ \\ ${ }^{1}$ Department of Textile Technology and Fashion Design, College of Science and Technology, Kaduna Polytechnic, \\ PMB 2021, Kaduna, Nigeria \\ ${ }^{2}$ Department of Textile Science and Technology, Ahmadu Bello University, Zaria, Nigeria \\ ${ }^{3}$ Department of Applied Science, College of Science and Technology, Kaduna Polytechnic, PMB 2021, Kaduna, Nigeria \\ Correspondence should be addressed to Yusuf Y. Lams; yyakubulams@yahoo.com
}

Received 17 April 2014; Revised 16 June 2014; Accepted 26 June 2014; Published 17 July 2014

Academic Editor: Claudio Cameselle

Copyright (C) 2014 Yusuf Y. Lams et al. This is an open access article distributed under the Creative Commons Attribution License, which permits unrestricted use, distribution, and reproduction in any medium, provided the original work is properly cited.

\begin{abstract}
The aim of this study was to synthesize disperse dyes in the derivative of 2-amino-4-chloro-5-formylthiazole by conventional diazotization and couplings with pyridone and resorcinol. The dyes were characterized by visible absorption spectroscopy, IR spectral studies, and ${ }^{1} \mathrm{H}$ and ${ }^{13} \mathrm{C}$ NMR. The pyridone and resorcinol substituted dyes exhausted well with good depth on $100 \%$ polyester fabrics with a shade of brown and purple colours, respectively. The heteroatom and the intrinsic conjugation in the thiazole structure results in high bathochromic shifts and lead to brightness of shades. The dyed fabrics showed very good to excellent wash fastness and moderate to good light and perspiration fastness properties.
\end{abstract}

\section{Introduction}

Textile dyes such as indigo can be derived from natural sources, while others such as disperse dyes which are meant for specific applications are obtained by synthesis. The dyes are classified according to their chemical constitution or method of application [1]. According to the colour index [2], disperse dye is a class of sparingly water soluble dyes originally introduced for dyeing cellulose acetate and usually applied from fine aqueous dispersion. Disperse dyes have also been defined as sparingly water soluble, nonionic dyes applied to hydrophobic fibres from aqueous dispersions [3]. Disperse dyes are classified as either nitroarylamine, azo, or anthraquinone. Almost all contain amino $\left(\mathrm{NH}_{2}\right)$ or substituted amino groups but do not contain solubilizing groups such as sulphonic acid $\left(\mathrm{SO}_{3} \mathrm{H}\right)$ groups. The most dominant group of disperse dyes is the azo disperse dyes which account for over $70 \%$ of all disperse dyes manufactured. Disperse dyes, though originally developed to dye cellulose acetate, are now usefully applied to other hydrophobic fibres such as polyester [4].
Although more hydrophobic than cellulose acetate, polyester is more readily dyeable by some of the dyes developed for acetate using different techniques of dyeing at high temperature or in the presence of swelling agents or carriers [5].

This study focused on synthesis of disperse dyes in the derivative of 2-amino-4-chloro-5-formylthiazole by conventional diazotization and couplings with pyridone and resorcinol. The 2-amino-4-chloro-5-formylthiazole provides the base heterocyclic diazo component [6-9]. Pyridone derivatives are relatively recent heterocyclic intermediates for the preparation of azo dyes because azo pyridone dyes produce bright hues and are suitable for dyeing polyester fabrics. Although synthesis and condensation of the formyl group in the derivatives of 2-amino-4-chloro-5-formylthiazole with the pyridone derivative have been reported by Bello [6], there seems to be no report in literature on the use of 3-cyano-4-methyl-6-hydroxy-1-( $3^{1}$-methoxypropyl)2-pyridone and resorcinol in the synthesis of disperse dyes. 


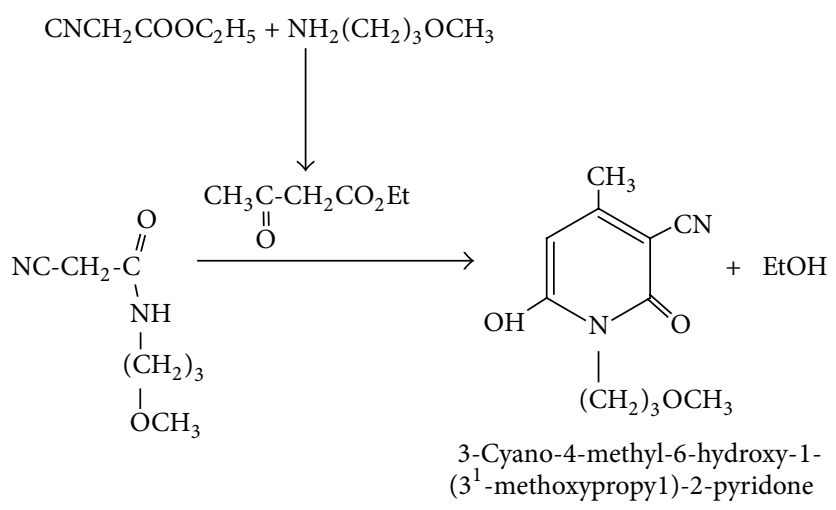

(1)

Scheme 1: Synthesis scheme for the synthesis of pyridone (P).

\section{Experimental}

2.1. Synthesis of 3-Cyano-4-methyl-6-hydroxy-1-(3 -methoxypropyl)-2-pyridone (Dye Intermediate) (Scheme 1). 3-Cyano4-methyl-6-hydroxy-1-( $3^{1}$-methoxypropyl)-2-pyridone was prepared by stirring a mixture of $28.2 \mathrm{~cm}^{3}$ ethyl cyanoacetate and $72.0 \mathrm{~cm}^{3} 3$-methoxy propylamine until a clear solution was obtained, and then $39.3 \mathrm{~cm}^{3}$ ethyl acetoacetate was added. The mixture was refluxed at $110^{\circ} \mathrm{C}$ for 9 hours.

Dilution and acidification of the solution produced the pyridone in good yield.

2.2. Synthesis of Diazo Component (2-Amino-4-chloro-5formylthiazole) (Scheme 2). 2-Amino-4-chloro-5-formylthiazole (4) was prepared by Villsmeier formylation of $30.4 \mathrm{~g}$ of 2-aminothiozolinone hydrochloride salt (2) which was in turn prepared by refluxing a mixture of $66 \mathrm{~g}$ ethyl chloroacetate and $40.2 \mathrm{~g}$ thiourea in $255 \mathrm{~cm}^{3}$ ethanol for 3 hours as summarized in Scheme 2. The aldehyde (4) was prepared by adding the hydrochloride salt to a cooled mixture of $154 \mathrm{~cm}^{3}$ dimethylformamide and $56 \mathrm{~cm}^{3}$ phosphorous oxychloride. The mixture was heated at $70^{\circ} \mathrm{C}$ for 24 hours. After adding the mixture to $240 \mathrm{~cm}^{3}$ of ice-water and hydrolyzing with $24 \mathrm{~g} / 80 \mathrm{~cm}^{3}$ solution of sodium hydroxide, the product (4) rapidly precipitated. It was purified by pouring the cake in water and adjusting the $\mathrm{pH}$ to 5 with sodium acetate. The product was obtained as a yellow solid in good yield.

2.3. Diazotization of 2-Amino-4-chloro-5-formylthiazole. Sodium nitrite $\left(2.8 \mathrm{~g}, 0.04\right.$ moles) was added to $30 \mathrm{~cm}^{3}$ cold concentrated sulphuric acid at such a rate that brown fumes were not evolved. After the addition, the mixture was warmed gradually on a water-bath to $65-70^{\circ} \mathrm{C}$ when all of the sodium nitrite went into solution. The solution was cooled externally to $5^{\circ} \mathrm{C}$ and diluted with $20 \mathrm{~cm}^{3}$ of $1: 4$ (by volume) mixture of propionic and acetic acid. 0.04 mole aminothiazole was added gradually to the nitrosylsulfuric acid paste at $0^{\circ} \mathrm{C}$ with vigorous stirring and the liquor was then stirred for $15 \mathrm{~min}$. maintaining the temperature at $10^{\circ} \mathrm{C}$.
The diazo solution was coupled to the various coupling components.

Coupling components:<smiles>COCCCCCn1c(O)cc(C)c(C#N)c1=O</smiles>

Pyridone (P)

(5)<smiles>Oc1cccc(O)c1</smiles>

Resorcinol (RSN)

(6)

2.4. Coupling of Diazotized 2-Amino-4-chloro-5-formylthiazole to Pyridone and Resorcinol (Scheme 3). 3-Cyano4-methyl-6-hydroxy-1-( $3^{1}$-methoxypropyl)-2-pyridone (1) $(1.50 \mathrm{~g}, 0.01 \mathrm{~mole})$ was dissolved in a solution of $\mathrm{KOH}(0.56 \mathrm{~g}$, $0.01 \mathrm{~mole}$ ) in $4 \mathrm{~mL}$ water. The resultant solution was cooled to $0-5^{\circ} \mathrm{C}$ and treated with a cold solution of the diazonium salt as prepared above. The same procedure was followed to prepare coupling solution with the resorcinol (RSN).

2.5. Characterization of the Dyes. The dyes were characterized by visible absorption spectroscopy using Unicam SP 800 spectrophotometer, IR spectral bands obtained from Pekin Elmer 100 FT-IR spectrophotometer, and ${ }^{1} \mathrm{H}$ and ${ }^{13} \mathrm{C} \mathrm{NMR}$ using Brucker-Advanced $400 \mathrm{MHz}$ FT-NMR spectrometer. 


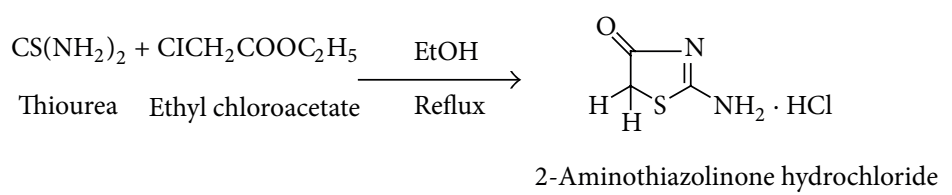

(2)

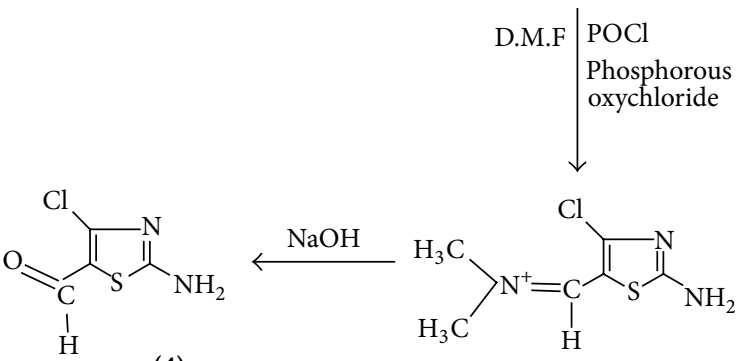

(4)

2-Amino-4-chloro-5-formylthiazole

(3)

(diazo component)

Scheme 2: Synthesis scheme for synthesizing 2-amino-4-chloro-5-formylthiazole.
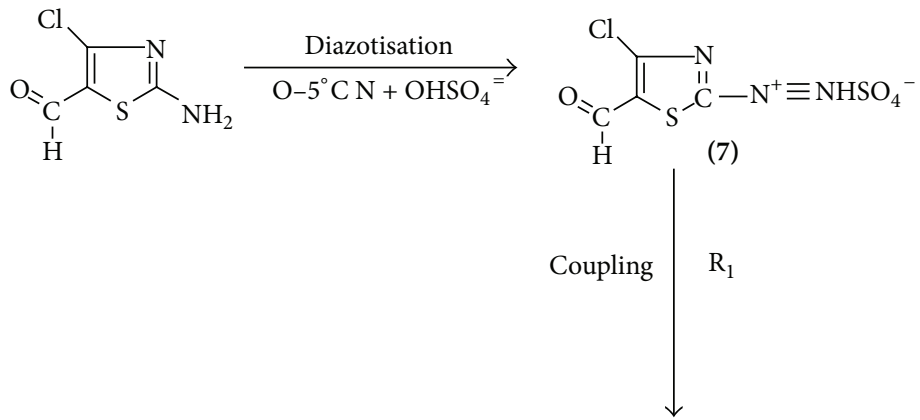

Where $\mathrm{R}_{1}$ is coupling component

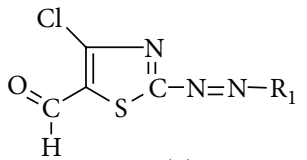

(8)

Scheme 3: Synthesis scheme for the dyes obtained from 2-amino-4-chloro-5-formylthiazole as the diazo component.

2.6. Dyeing. The dye bath of $50 \mathrm{~mL}$ was made up of the dye (2\% o.w.f.), $1.5 \mathrm{~mL}$ carrier (chlorobenzene), and $1 \mathrm{~mL}$ dispersing agent (Albatex PON). $1 \mathrm{~g}$ of the fabric after being wetted and thoroughly squeezed to remove excess water was immersed into the bath at $50^{\circ} \mathrm{C}$ and allowed to reach the boil within 15 mins. Dyeing was continued at the boil for $1 \mathrm{hr}$ with constant agitation. At the end of dyeing, the substrate was removed, squeezed, and rinsed thoroughly under a running tap water and allowed to dry at room temperature.

2.7. Reduction Clearing. The dyed material was treated in a bath containing $1.5 \mathrm{~g} / \mathrm{L}$ dispersing agent, $2 \mathrm{~g} / \mathrm{L}$ caustic soda, and $2 \mathrm{~g} / \mathrm{L}$ sodium dithionite at $60^{\circ} \mathrm{C}$ for 30 minutes. This was aimed at removing unfixed dye and carrier residues that may be left on the fabric after dyeing [10].

\section{Results}

The diazo component used is as shown next:<smiles>[R]N=Nc1nc(Cl)c(C=O)s1</smiles>

where $\mathrm{R}_{1}$ is the coupling component.

\section{Discussion}

The UV-visible and IR spectral characteristics of the dyes showed that dyes 1 and 2 absorbed light at high wavelengths 
TABLE 1: Yield, color, and melting points of dyes derived from the diazo component.

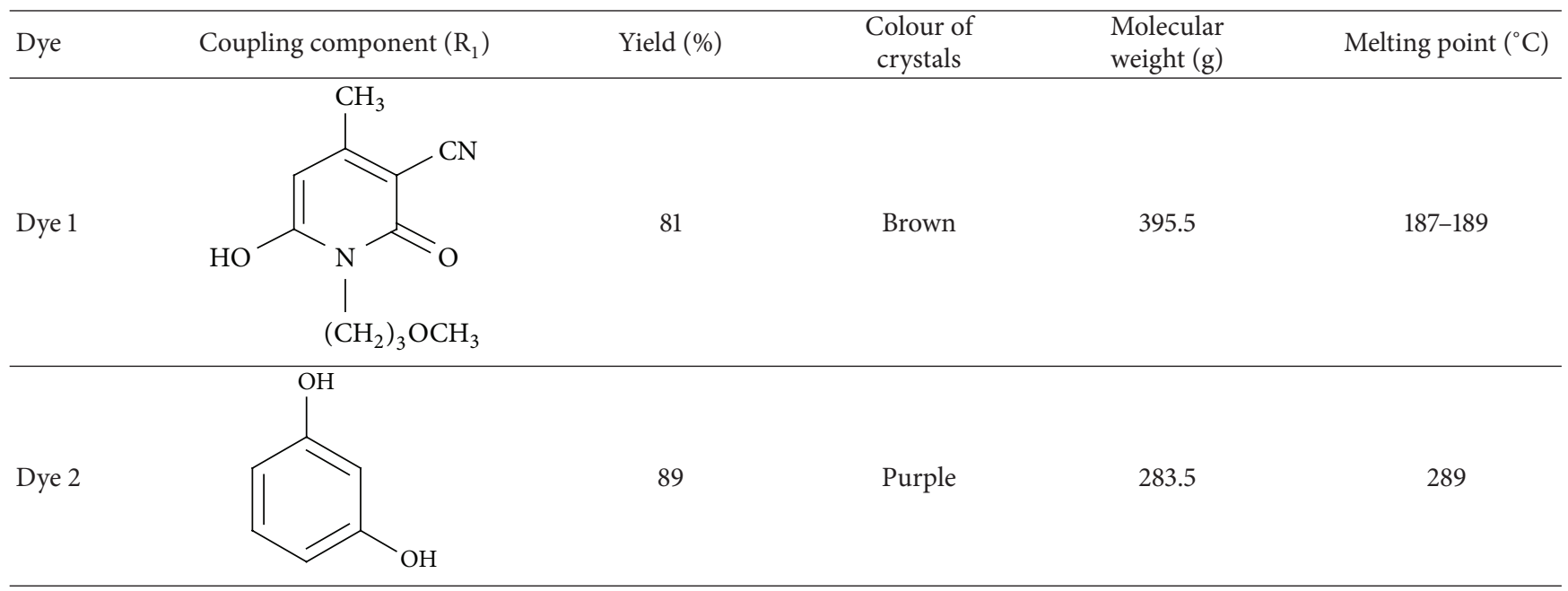

TABLE 2: UV spectral properties of dyes in different solvents.

\begin{tabular}{|c|c|c|c|c|c|c|}
\hline Dye & $\begin{array}{c}\text { Ethanol (a) } \\
\lambda_{\max }\end{array}$ & $\begin{array}{l}\text { Acetone (b) } \\
\qquad \lambda_{\max }\end{array}$ & $\begin{array}{c}\text { Dimethylformamide } \\
(\mathrm{DMF})(\mathrm{c}) \\
\lambda_{\max } \\
\end{array}$ & $\begin{array}{c}\text { Ethanol }+\mathrm{HCl}(\mathrm{d}) \\
\lambda_{\max } \\
\end{array}$ & $\begin{array}{l}\text { Change in } \lambda_{\max } \\
\quad(\mathrm{a}-\mathrm{d})\end{array}$ & $\begin{array}{l}\text { Molar extinction } \\
\text { coefficient in DMF } \\
\mathrm{L} \mathrm{Mol}^{-1} \mathrm{~cm}^{-1} \times 10^{4}\end{array}$ \\
\hline Dye 1 & 549.0 & 532.0 & 552.0 & 527.0 & -22 & 4.340 \\
\hline Dye 2 & 470.2 & 504.5 & 496.0 & 472.0 & +1.5 & 1.990 \\
\hline
\end{tabular}

TABLE 3: Wash, light, and perspiration fastness of dyes on polyester.

\begin{tabular}{|c|c|c|c|c|c|c|c|}
\hline \multirow{3}{*}{ Dye } & \multicolumn{2}{|c|}{ Fastness to wash } & \multicolumn{5}{|c|}{ Fastness to perspiration } \\
\hline & \multirow{2}{*}{$\mathrm{CSH}$} & \multirow{2}{*}{ STN } & \multirow[t]{2}{*}{ Fastness to light } & \multicolumn{2}{|c|}{ ACID } & \multicolumn{2}{|c|}{ ALKALI } \\
\hline & & & & $\mathrm{CSH}$ & STN & $\mathrm{CSH}$ & STN \\
\hline Dye 1 & 5 & 5 & 5 & 4 & 4 & 4 & $3-4$ \\
\hline Dye 2 & 4 & $4-5$ & 3 & 2 & 2 & 2 & $2-3$ \\
\hline
\end{tabular}

CSH: change in shade; STN: stain.

up to $549.0 \mathrm{~nm}$ (dye 1) and $504.5 \mathrm{~nm}$ (dye 2) (Table 1). The presence of the main functional groups such as carbonyl $(\mathrm{C}=\mathrm{O})$, azo $(\mathrm{N}=\mathrm{N})$, nitrile $(\mathrm{C}-\mathrm{N})$, cyano $(\mathrm{C} \equiv \mathrm{N})$, hydroxyl $(\mathrm{OH})$, and carbon-chloride single bond $(\mathrm{C}-\mathrm{Cl})$ in the structures of the dyes was established by IR spectral bands.

Solvatochromism describes the ability of a chemical substance to change colour due to a change in solvent polarity. Negative solvatochromism corresponds to hypsochromic shift with increasing solvent polarity and positive solvatochromism corresponds to bathochromic shift with increasing solvent polarity. The sign of the solvatochromism depends on the difference in dipole moment between the ground and excited states of the chromophore.

The solvatochromic properties of the dyes were measured in acetone, dimethylformamide (DMF), and ethanol [11]. The results in Table 2 showed that dye 1 was absorbed at much higher wavelength in DMF, an indication that DMF has greater polarity towards the dye than the other solvents. Since polarities of the ground and excited state of a chromophore are different, a change in the solvent polarity will lead to differential stabilization of the ground and excited states and thus a change in the energy gap between these electronic states. Consequently, variations in the position, intensity, and shape of the absorption spectra can be direct measures of the specific interactions between the solute and solvent molecules. The halochromism (effect of few drops of acid on the visible absorption band) of the dyes was studied in ethanol. The dyes exhibited positive and negative halochromism, respectively, on addition of one drop of hydrochloric acid to ethanol (Table 2) with visible absorption maximum at $527 \mathrm{~nm}$ and $472 \mathrm{~nm}$, corresponding to halochromism shifts of $-22 \mathrm{~nm}$ and $+1.5 \mathrm{~nm}$ for dyes 1 and 2 , respectively. The negative halochromism exhibited by dye 1 occurred due to decrease in bathochromic shift arising from the release of electrons from $\left(\mathrm{CH}_{2}\right)_{3} \mathrm{OCH}_{3}$ into the aromatic ring of the coupling component (pyridone). Dye 2 gave a positive halochromism by a shift of $+1.5 \mathrm{~nm}$. This is the effect of the $\mathrm{OH}$ groups on the resorcinol.

The structures of the dyes (Figure 1) were established and confirmed by proton $\left({ }^{1} \mathrm{H}\right)$ and carbon $\left({ }^{13} \mathrm{C}\right) \mathrm{NMR}$. 
TAble 4: Proton $\left({ }^{1} \mathrm{H}\right)$ and carbon $\left({ }^{13} \mathrm{C}\right)$ NMR characterization of dye 1 in DMSO ( $\left.\delta \mathrm{ppm}\right)$.

\begin{tabular}{|c|c|c|c|c|c|}
\hline \multirow{2}{*}{ Carbon } & \multirow{2}{*}{ DEPT } & \multicolumn{2}{|c|}{ Proton $\left({ }^{1} \mathrm{H}\right)$} & \multicolumn{2}{|c|}{ Carbon $\left({ }^{13} \mathrm{C}\right)$} \\
\hline & & $\mathrm{Cal}(\delta \mathrm{h})$ & $\operatorname{Expt}(\delta \mathrm{h})$ & $\operatorname{Cal}(\delta \mathrm{c})$ & $\operatorname{Expt}(\delta c)$ \\
\hline 2 & $\mathrm{C}$ & - & - & 154.76 & 157.62 \\
\hline 4 & $\mathrm{C}$ & - & - & 138.80 & 144.84 \\
\hline 5 & $\mathrm{C}$ & - & - & 131.40 & 128.61 \\
\hline 6 & $\mathrm{CH}$ & 9.84 & 9.91 & 188.70 & 181.62 \\
\hline $2^{1}$ & $\mathrm{C}$ & - & - & 156.4 & 159.14 \\
\hline $3^{1}$ & $\mathrm{C}$ & - & - & 115.5 & 114.18 \\
\hline $4^{1}$ & $\mathrm{C}$ & - & - & 166.3 & 171.34 \\
\hline $5^{1}$ & $\mathrm{C}$ & - & - & 74.10 & 69.56 \\
\hline $7^{1}$ & $\mathrm{CH}_{2}$ & 3.41 & 3.40 & 38.00 & 39.03 \\
\hline $8^{1}$ & $\mathrm{CH}_{2}$ & 1.73 & 1.77 & 27.71 & 27.07 \\
\hline $9^{1}$ & $\mathrm{CH}_{2}$ & 3.37 & 3.38 & 72.10 & 69.56 \\
\hline $10^{1}$ & $\mathrm{CH}_{3}$ & 3.30 & 3.09 & 59.30 & 57.81 \\
\hline $12^{1}$ & $\mathrm{CH}_{3}$ & 2.21 & 2.55 & 52.8 & 16.25 \\
\hline
\end{tabular}

TAble 5: Proton $\left({ }^{1} \mathrm{H}\right)$ and carbon $\left({ }^{13} \mathrm{C}\right)$ NMR characterization of dye 2 in DMSO ( $\left.8 \mathrm{ppm}\right)$.

\begin{tabular}{|c|c|c|c|c|c|}
\hline \multirow{2}{*}{ Carbon } & \multirow{2}{*}{ DEPT } & \multicolumn{2}{|c|}{ Proton $\left({ }^{1} \mathrm{H}\right)$} & \multicolumn{2}{|c|}{ Carbon $\left({ }^{13} \mathrm{C}\right)$} \\
\hline & & $\mathrm{Cal}(\delta \mathrm{h})$ & $\operatorname{Expt}(\delta \mathrm{h})$ & $\mathrm{Cal}(\delta \mathrm{c})$ & $\operatorname{Expt}(\delta \mathrm{c})$ \\
\hline 2 & $\mathrm{C}$ & - & - & 154.7 & 149.86 \\
\hline 4 & $\mathrm{C}$ & - & - & 139.0 & 129.65 \\
\hline 5 & $\mathrm{C}$ & - & - & 115.0 & 119.92 \\
\hline 6 & $\mathrm{CH}$ & 9.61 & 9.79 & 188.7 & 189.72 \\
\hline $1^{1}$ & $\mathrm{C}$ & - & - & 115.9 & - \\
\hline $2^{1}$ & $\mathrm{C}$ & - & - & 153.2 & 131.54 \\
\hline $3^{1}$ & $\mathrm{CH}$ & 6.2 & 7.17 & 104 & - \\
\hline $4^{1}$ & $\mathrm{C}$ & - & - & 156 & 132.72 \\
\hline $5^{1}$ & $\mathrm{CH}$ & 6.3 & 7.85 & 109 & - \\
\hline $6^{1}$ & $\mathrm{CH}$ & 6.9 & 7.82 & 125.4 & 124.52 \\
\hline
\end{tabular}

4.1. NMR Analysis of Dye 1. From the NMR spectra data presented in Table 4 ,

${ }^{13} \mathrm{C}-\mathrm{NMR}$ revealed 15 signals corresponding to 15 carbon atoms;

${ }^{1} \mathrm{H}-\mathrm{NMR}$ revealed 14 signals corresponding to 14 hydrogen atoms.

DEPT spectra indicate the following:

90 revealed $(1 \mathrm{CH}=1 \mathrm{C}, 1 \mathrm{H})$,

135 revealed $\left(3 \mathrm{CH}_{2}=3 \mathrm{C}, 6 \mathrm{H}\right)$,

135 revealed $\left(2 \mathrm{CH}_{3}=2 \mathrm{C}, 6 \mathrm{H}\right)$.

From the dye structure in Figure 2, there are 7 quaternary carbon atoms.

The presence of $\mathrm{OH}$ was cited at carbon $6^{1}(\delta \mathrm{h}=$ $4.76 \mathrm{ppm})$.

The presence of $\mathrm{CN}$ was cited at carbon $11^{1}(\delta \mathrm{c}=$ $125.50 \mathrm{ppm})$.
4.2. NMR Analysis of Dye 2. From the NMR spectra data for dye 2 (Table 5),

${ }^{13} \mathrm{CNMR}$ revealed 10 signals corresponding to 10 carbon atoms;

${ }^{1} \mathrm{H}$ NMR revealed 6 signals corresponding to 6 hydrogen atoms;

DEPT 90 revealed $4 \mathrm{CH}=4 \mathrm{C}, 4 \mathrm{H}$;

DEPT 135 did not reveal the presence of $\mathrm{CH}_{2}$ and $\mathrm{CH}_{3}$, thereby confirming the absence of ethyl and methyl groups in the structure of dye 2 (Figure 3 ).

From the structure of the dye, there are six (6) quaternary carbon atoms. The presence of $\mathrm{OH}$ was cited at carbons $2^{1}$ and $4^{1}(\delta \mathrm{h}=8.23, \delta \mathrm{h}=3.40, \delta \mathrm{c}=131.54$, and $\delta \mathrm{c}=132.72)$, respectively, thereby confirming the two $\mathrm{OH}$ groups in the structure of dye 2 .

On application of the dyes to polyester, the dyes exhausted well, gave leveled dyeing, and provided good shades. This is attributed to factors such as the nature and composition of diazo and coupling components, type and position of substituents on the heteroatom and carboxylic rings, and 
<smiles>CCCCCn1c(O)c(N=Nc2nc(Cl)c(C=O)s2)c(C)c(C#N)c1=O</smiles>

Dye 1<smiles>O=Cc1sc(N=Nc2ccc(O)cc2O)nc1Cl</smiles>

Dye 2

Figure 1: Structures of dyes 1 and 2.<smiles>COCCCn1c(O)c(N=Nc2nc(Cl)c(C=O)s2)c(C)c(C#N)c1=O</smiles>

Figure 2: Structure of dye 1 showing its carbon positions.<smiles>O=Cc1sc(N=Nc2ccc(O)cc2O)nc1Cl</smiles>

FIGURE 3: Structure of dye 2 showing its carbon positions.

planarity of the dyes. The derivative of the diazo component used generally produced deep brown and purple shades.

The dyes exhausted well on the polyester fabrics and exhibited high molar extinction coefficients in the range of $1.990-4.340 \times 10^{4} \mathrm{~L} \mathrm{~mol}^{-1} \mathrm{~cm}^{-1}$ as shown in Table 2 .

The dyeing properties such as fastness to washing, light, and perspiration of the dyes were assessed and the results as presented in Table 3 indicate that the dyes have very high fastness to wash, light and perspiration. This observation is similar to that for dyes from other sources $[4,12]$.

\section{Conclusion}

Disperse dyes were produced by coupling diazotized 2amino-4-chloro-5-formylthiazole to pyridone and resorcinol. The spectral studies of the dyes indicated that they absorbed and transmitted light well in the visible region.
The proton $\left({ }^{1} \mathrm{H}\right)$ and carbon $\left({ }^{13} \mathrm{C}\right)$ NMR of the dyes further confirmed their structure and content as new dyes derived from 2-amino-4-chloro-5-formylthiazole. The dyes provided brown and purple shades on fibre and offered excellent affinity and intensity of colour. The heteroatom and the intrinsic conjugation in the thiazole structure result in high bathochromic shifts and lead to brightness of shades. The dyes showed very good exhaustion, leveled and uniform dyeing.

\section{Conflict of Interests}

The authors declare that there is no conflict of interests regarding the publication of this paper.

\section{Acknowledgment}

The authors are grateful to the Department of Chemistry, University of Kwazulu-Natal, South Africa, for granting the permission to carry out the NMR and FT-IR analysis of the dyes in the instrumentation laboratory.

\section{References}

[1] N. E. Abrahat, Dyes and Their Intermediates, Edward Arnold, London, UK, 1977.

[2] CI (Colour Index), Chemical Constitutions, Society of Dyers and Colourists (SDC) and American Association of Textile Chemists and Colourists (AATCC), 23rd edition, 1971.

[3] M. P. Philip, Webster's Online Dictionary, Roster edition, 2005, http://www.webster-online-dictionary.org/definition/ DISPERSE+DYES.

[4] C. R. Meena, R. V. Adivarekar, and N. Sekar, "Synthesis and application of vinylsulphone disperse reactive dyes for polyester," International Journal of ChemTech Research, vol. 5, no. 2, pp. 585-591, 2013.

[5] CI (Colour Index), Chemical Constitutions, Society of Dyers and Colourists (SDC) and American Association of TextileChemists and Colourists (AATCC), 43rd edition, 1971.

[6] K. A. Bello, "Long wavelength absorbing azo dyes derived from 2-amino-4-chloro-5-formylthiazole as diazo component," Dyes and Pigments, vol. 27, no. 1, pp. 45-54, 1995.

[7] H. R. Maradiya and V. S. Patel, "Synthesis and application of disperse dyes based on 2-aminothiazole derivatives," Chemistry of Heterocyclic Compounds, vol. 39, no. 3, pp. 404-409, 2003.

[8] M. M. El-Molla, Z. H. Ismaeil, F. M. A. Soliman, H. Shaimaa, and A. Monem, "Synthesis of several newly disperse dyes 
and their application in textile printing," Journal of the Textile Association, vol. 74, no. 1, pp. 18-25, 2013.

[9] S. K. Zadafiya, J. H. Tailor, and G. M. Malik, "Disperse dyes based on thiazole, their dyeing application on polyester fiber and their antimicrobial activity," Journal of Chemistry, vol. 2013, Article ID 851418, 5 pages, 2013.

[10] P. O. Nkeonye, Fundamental Principles of Textile Dyeing, Printing and Finishing, Ahmadu Bello University Press, 1987.

[11] A. Marini, M. Aurora, B. Alessendro, and M. Benedetha, "What is solvatochromism?" The Journal of Physical Chemistry B, vol. 114, no. 51, pp. 17128-17135, 2010.

[12] P. Parvizi, A. Khosravi, S. Moradian, and K. Gharanjig, "Synthesis and application of some alkali-clearable azo disperse dyes based on naphthalimide derivatives," Journal of the Chinese Chemical Society, vol. 56, no. 5, pp. 1035-1042, 2009. 

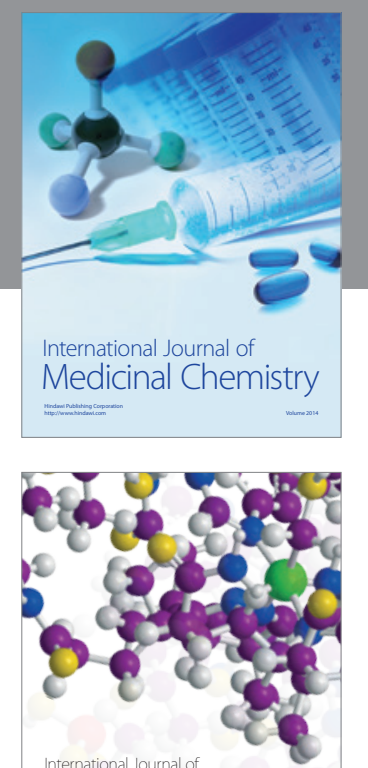

\section{Carbohydrate} Chemistry

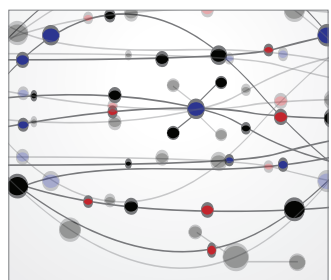

The Scientific World Journal
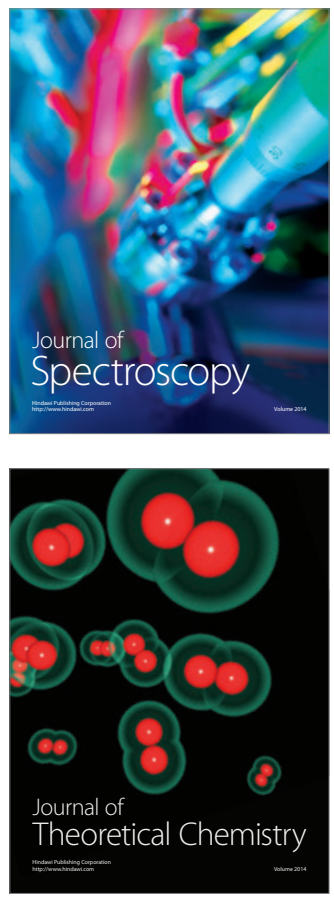
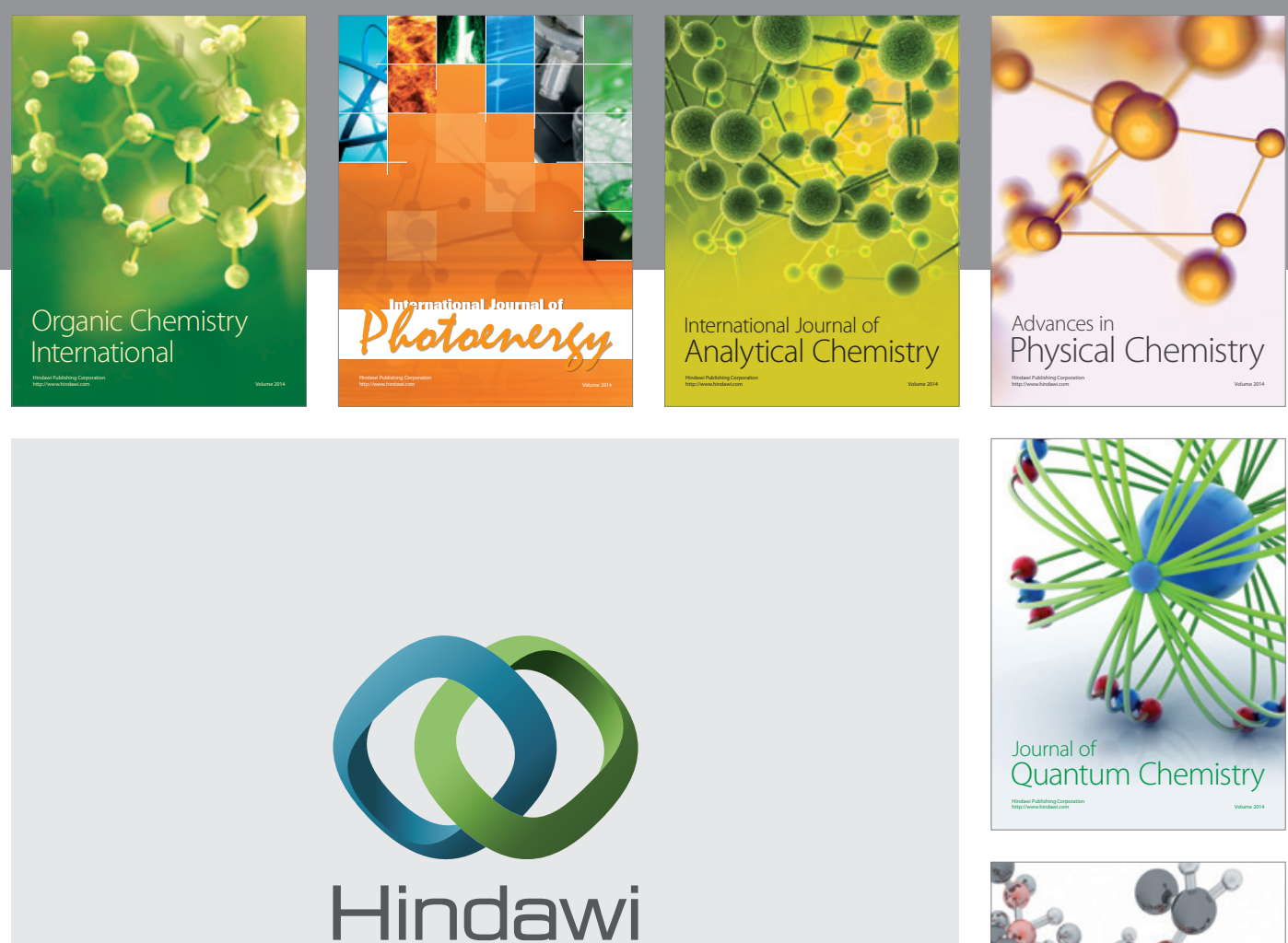

Submit your manuscripts at

http://www.hindawi.com

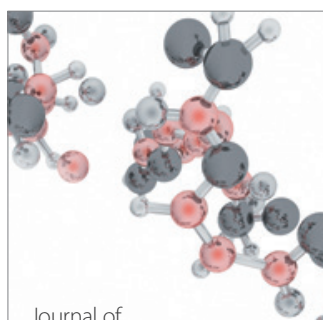

Analytical Methods

in Chemistry

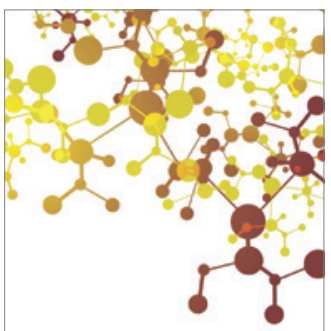

Journal of

Applied Chemistry

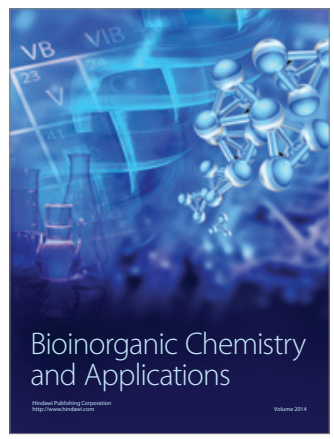

Inorganic Chemistry
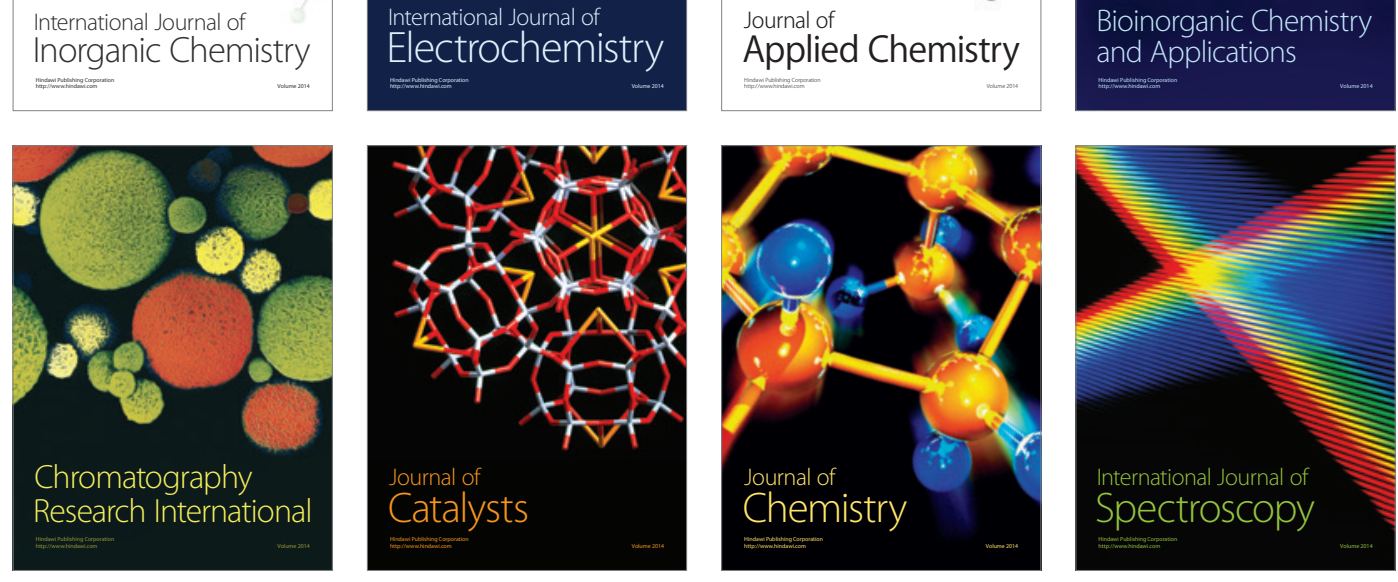